\title{
Model Rancangan Way Finding Masjid Al - Khoory Universitas Muhammadiyah Surabaya
}

\author{
Muhammad Deriel Ari Pranata ${ }^{1}$, Zuraida $^{2}$, Vippy Dharmawan ${ }^{3}$ \\ ${ }^{1}$ Jurusan Arsitektur, Fakultas Teknik, Universitas Muhammadiyah Surabaya \\ Email: ․m. $^{\text {mummaderiel@gmail.com }}$
}

\begin{abstract}
The function of an artificial environment will run optimally if the existing way finding system can provide comfort for the users of the environment. Way finding is the process of moving users from the old location to the new location with the help of the elements that are around them. The mosque which is an artificial environment that is functioned as a place of worship for Muslims must be located in a strategic location, so that it is easily seen and reached by Muslims when they want to worship. Not in line with this, it turns out that the location of the Al-Khoory Mosque, University of Muhammadiyah Surabaya, is less strategic and makes mosque users, especially new users confused, to find the location of Al-Khoory Mosque, University of Muhammadiyah Surabaya. This is evidenced by the answers of respondents who agree that the location of the mosque is less strategic so that it makes confusion to find the location of the mosque. This study will use a qualitative method with data collection techniques using a likert scale. The design model of the way finding system is the right solution for the problem of the artificial environment when it does not have a strategic location, architectural elements in the form of way finding aspects can help users to find the desired location without experiencing disorientation.
\end{abstract}

Keywords: Model, Design, System, Way finding, Mosque

\begin{abstract}
Abstrak. Fungsi dari sebuah lingkungan buatan akan berjalan secara optimal apabila sistem way finding yang ada dapat memberikan kenyamanan bagi pengguna lingkungan tersebut. Way finding adalah proses perpindahan pengguna dari lokasi yang lama menuju lokasi yang baru dengan bantuan elemen - elemen yang ada disekitarnya. Masjid yang merupakan sebuah lingkungan buatan yang difungsikan untuk tempat beribadah umat muslim haruslah terletak di lokasi yang strategis, agar mudah terlihat dan dijangkau oleh muat muslim ketika ingin beribadah. Tidak sejalan dengan hal tersebut, ternyata letak Masjid Al-Khoory Universitas Muhammadiyah Surabaya, kurang strategis dan membuat pengguna masjid khususnya pengguna baru kebingungan untuk menemuka lokasi Masjid Al-Khoory Universitas Muhammadiyah Surabaya. Hal tersebut dibuktikan dari jawaban responden yang menyetujui letak masjid kurang strategis sehingga membuat kebingungan untuk menemukan lokasi masjid tersebut. Penelitian ini akan menggunakan metode kualitatif dengan teknik pengambilan data menggunakan skala likert. Model rancangan way finding merupakan solusi yang tepat bagi permasalahan lingkungan buatan ketika tidak memiliki lokasi yang strategis, elemen - elemen arsitektur yang berwujud aspek way finding dapat membantu pengguna untuk menemukan lokasi yang diinginkan tanpa mengalami dis-orientsasi.
\end{abstract}

Kata Kunci: Model, Rancangan, Sistem, Way finding, Masjid

\section{Pendahuluan}

Universitas Muhammadiyah Surabaya (UM Surabaya) adalah salah satu perguruan tinggi swasta milik amal usaha Muhammadiyah yang berlokasi di Surabaya Timur. Untuk mendukung kelancaran kegiatan belajar mengajar kampus ini memiliki berbagai macam fasilitas. Salah satu fasilitas yang ada pada kampus ini, adalah Masjid Al-Khoory. Masjid ini merupakan satu - satunya fasilitas ibadah yang dimiliki oleh UM Surabaya. Lokasi masjid ini terletak di bagian kiri kampus dan berada dibelakang gedung A yang membuatnya sedikit tersembunyi. Selain itu masa bangunan di sekitar masjid ini memiliki ukuran yang lebih tinggi dan lebih besar. Hal ini memungkinkan civitas UM Surabaya kebingungan dalam menemukan jalan menuju Masjid Al-Khoory, Hal lain yang perlu dicermati, penempatan lokasi masjid yang 
harus terletak di tempat yang strategis. Penempatan ini bertujuan agar mudah ditemukan oleh pengguna civitas kampus, terutama civitas baru UM Surabaya.

Diperlukan suatu penelitan purna huni atau post occupancy evaluation (POE) terhadap permasalahan yang terjadi pada Masjid Al-Khoory UM Surabaya. POE ini nantinya akan berfokus pada legibility dan imageability sistem way finding yang ada pada Masjid Al-Khoory, sehingga akan diketahui seberapa optimalkah fungsi dari Masjid Al-khoory sebagai fasilitas kampus. POE akan dilakukan dengan melibatkan seluruh civitas akademika UM Surabaya baik mahasiswa, tenaga akademi, maupun tenaga teknis yang menggunakan Masjid Al-khoory UM Surabaya

Hasil penelitian purna huni ini akan digunakan untuk menyusun model sistem way finding Masjid AL-Khoory UM Surabaya, sehingga meskipun tata letak masjid tersebut berada di area yang cukup tersembunyi akan mudah ditemukan oleh pengguna. Berdasarkan hasil penelitian ditemukan bahwa perlu adanya sistem way finding yang baik bagi lingkungan UM Surabaya, di mana Gedung At-Tauhid merupakan landmark dari UM Surabaya karena terlihat dari berbagai arah di lingkungan kampus baik di dalam maupun di luar lingkungan.

\subsection{Konsep Way Finding dalam Desain Masjid}

Way finding merupakan kemampuan pengguna dalam menemukan suatu lokasi (Passini, 1984). Kemampuan ini berguna ketika pengguna ingin menuju ke lokasi atau ingin menemukan suatu lokasi yang berlum pernah dikunjungi sebelumnya (Hantari, 2020). Dengan mengumpulkan informasi sekitar seperti papan penanda, pengguna dapat menemukan jalur yang tepat untuk menuju lokasi yang diinginkan.

Dalam dunia arsitektur way finding dapat diartikan sebagai kemampuan pengguna untuk mencapai suatu lokasi (Passini, 1984). Passini (1984) juga menjelaskan keberhasilan proses ini dipengaruhi oleh 3 faktor yaitu, kemampuan individu, proses kognisi dan peta kognisi yang dibangun di dalam individu, dan enviromental informasi. Pengguna dapat mencapai lokasi yang diinginkan melalui suatu proses beripikir yang di pengaruhi oleh pengalaman, persepsi, dan elemen - elemen arsitektur disekitarnya.

Prinsip way finding dibagi menjadi 3 tahap yaitu mempertimbangkan, pengambilan keputusan dan memproses informasi (Sevinc \& Bozkurt, 2015). Sementara itu menurut Downs \& Stea (1973) membagi way finding kedalam 4 tahapan yaitu:orientation, route selection, route control, dan recognition of destination. Elemen - elemen arsitektur yang merupakan faktor keberhasilan proses way finding dapat meliputi komponen terbangun, termasuk perencanaan tata ruang, artikulasi fitur pemberian bentuk, sistem sirkulasi dan komunikasi lingkungan (Susan Hunter, 2010).

Di dalam sebuah kota terdapat sebuah citra yang membantu penghuni kota tersebut dapat berpindah lokasi atau menemukan lokasi yang ingin dituju dengan cepat dan mudah. Adapun 5 elemen arsitekur penunjang citra kota menurut Kevin Lynch (1960) adalah sebagai berikut : (1) pathway; (2) node; (3) landmark; (4) district; dan (5) edge.

Sementara itu ternyata Passini (1992) juga menemukan elemen citra kota tersebut kedalam skala bangunan. Berupa:

1. Path dapat berupa koridor, tangga, atau eskalator passini juga membagi path menjadi dua jenis karena sifatnya yaitu horizontal dan vertical

2. Edges dalam skala bangunan dapat berupa dinding yang berfungsi sebagai pembatas bangunan antara bagian dalam dan luar.

3. Nodes dalam skala bangunan merupakan pertemuan antara jalan yang ada pada bangunan tersebut, atau pertemuan antara sirkulasi.

4. District dalam sebuah bangunan, seperti zona bermain, zona perbelanjaan, atau seperti foodcourt pada pusat perbelanjaan.

5. Landmark pada skala bangunan dapat menjadi patung, dekorasi, restoran fastfood 
Seorang arsitek dapat membaginya kedalam empat tahapan agar rancangan way finding dapat digunakan secara optimal yaitu, identifying and space/indentifikasi dan menandai ruang, group spacel pengelompokan ruang, linking and ogranization space/menghubungkan dan mengelompokkan ruang, dan "communcating this information to user"/ menginformasikan informasi terhadap pengguna (Hunter, 2010).

Kenyamanan untuk dapat memenuhi kebutuhan sangatlah terganjung pada kejelasan sistem informasi untuk dapat mengenali area sekitarnya (Griffin, 2006). Sistem penanda merupakan sistem yang terdiri dari kumpulan penanda (sign) yang sengaja dirancang untuk membantu memandu manusia dalam mengerti suatu area lingkungan tertentu (Follis dan Hammer, 1979).

Dalam mendesain penanda perlu memperhatikan beberapa aspek yang ada seperti jarak keterbacaan, tinggi penanda, tulisan (huruf) yang digunakan, kontras dan warna (Griffin, 2006). Bentuk dari sistem penanda juga memiliki 3 kategori dasar yaitu untuk informasi berbentuk persegi, peraturan berbentuk lingkaran, dan peringatan berbentuk segitiga (Griffin, 2006).

Dikarenakan proses way finding dipengaruhi oleh kondisi psikologis pengguna maka kesalahan dan kurangnya penerapan way finding pada suatu lingkungan akan menyebabkan dis-orientas. maka Kesalahan dan kurangnya penerapan way finding juga menyebabkan pengguna mengalami pengalaman yang kurang baik bisa juga pengguna akan mengalami stress karena tidak dapat menemukan jalur yang benar karena kurangnya informasi yang didapat dari lingkungan sekitar (Beaumont, dkk. 1984).

Model way finding yang baik adalah model way finding yang dapat dibaca, dilihat, dan tidak susah ditemukan oleh pengguna, selain itu juga harus memperhatikan aspek arsitektur dan desain agar terlihat menarik dan menyatu dengan elemen sekitar.

Masjid memiliki arti tempat sujud, sebutan lain dari masjid yang umum digunakan di Indonesia adalah mushollah, langgar atau surau. Istilah - istilah tersebut berlaku pada bangunan yang menyerupai masjid yang tidak digunakan untuk shalat jum'at dan biasanya berukuran kecil. Masjid juga memiliki fungsi primer dan sekunder, fungsi primer masjid meliputi ibadah seperti shalat dan i'tikaf dan fungsi sekunder meliputi segala kegiatan pendukung yang diselenggarakan di masjid yang pada hakekatnya juga merupakan ibadah atau bisa disebut ghairu maghdah (Rifa'i dan Fakhruroji, 2005). Fungsi pendukung haruslah mampu mengikuti perkembangan jaman, hal ini membuat fungsi pendukung bersifat dinamis.

Di dalam Islam juga terdapat anjuran untuk menghias masjid agar terlihat lebih indah. Kenyataan dalam Islam bahwa sesungguhnya Allah Maha Indah dan menyayangi keindahan dan bahwa seni adalah keindahn yang didukung oleh sunnah nabi tersebut mendorong adanya hiasan dalam masjid (Husain, 2011). Hiasan - hiasan ini dapat berupa motif floral atau tumbuh - tumbuhan, dalam banyak bentuk penyerdahanaan, mengisi bagian - bagian konstruksi, dinding, kolom, balok (Gazalba, 1994). Selain itu kaligrafi menjadi elemen yang oleh banyak orang dianggap menyatu dan harus ada didalam sebuah msjid. Kaligrafi merupakan seni menulis huruf. (Sumalyo, 2006).

\section{Metode Penelitian}

Muhadjir (2002) membedakan mengenai metodologi penelitian dengan metode penelitian, menurutnya metodologi penelitian merupakan suatu hal yang berbicara tentang teori dan konsep konsep metode penelitian, sedangkan metode penelitian mengacu pada cara teknis untuk melakukan pengumpulan data.

Metode penelitian diartikan sebagai cara yang dipakai oleh para peneliti untuk memecahkan masalah dan mencari jawaban atas pertanyaan - pertanyaan penelitian (Taylor dan Bogdan, 1984). Data penelitian terdiri dari dua jenis yaitu data primer dan data sekunder. Data primer adalah data yang didapat melalui pengamatan langsung, wawancara dan, penyebaran kuisioner, sedangkan data sekunder merupakan data yang didapat melalui literatur. Teknik pengumpulan data primer yang digunakan yaitu, pengumpulan literatur atau dokumen, observasi, dan penyebaran kuisioner. Penelitan purna huni atau post occupancy evaluation (POE) merupakan penelitian terhadap suatu objek yang telah ada yang bertujuan untuk permasalahan yang terjadi (Afrizal, 2016). Pada penelitian ini akan digunakan untuk menemukan masalah yang ada pada Masjid Al-Khoory UM Surabaya.

Penelitian ini menggunakan pengumpulan data skala Likert, dimana menurut Sugiyono (2014) digunakan untuk mengukur sikap, pendapat, dan persepsi sesseorang atau sekelompok orang tentang 
fenomena sosial. Penggunaan teknik pengumpulan data tersebut disesuaikan dengan sasaran penelitian, sehingga nantinya didapatkan rangkuman hasil pengamatan yang digunakan untuk menyusun model rancangan way finding Masjid Al-Khoory.

\section{Hasil dan Pembahasan}

Gambar 1 merupakan plotting Layout UM Surabaya dalam wujud 2D, lengkap dengan notasi mengenai block plan nya.

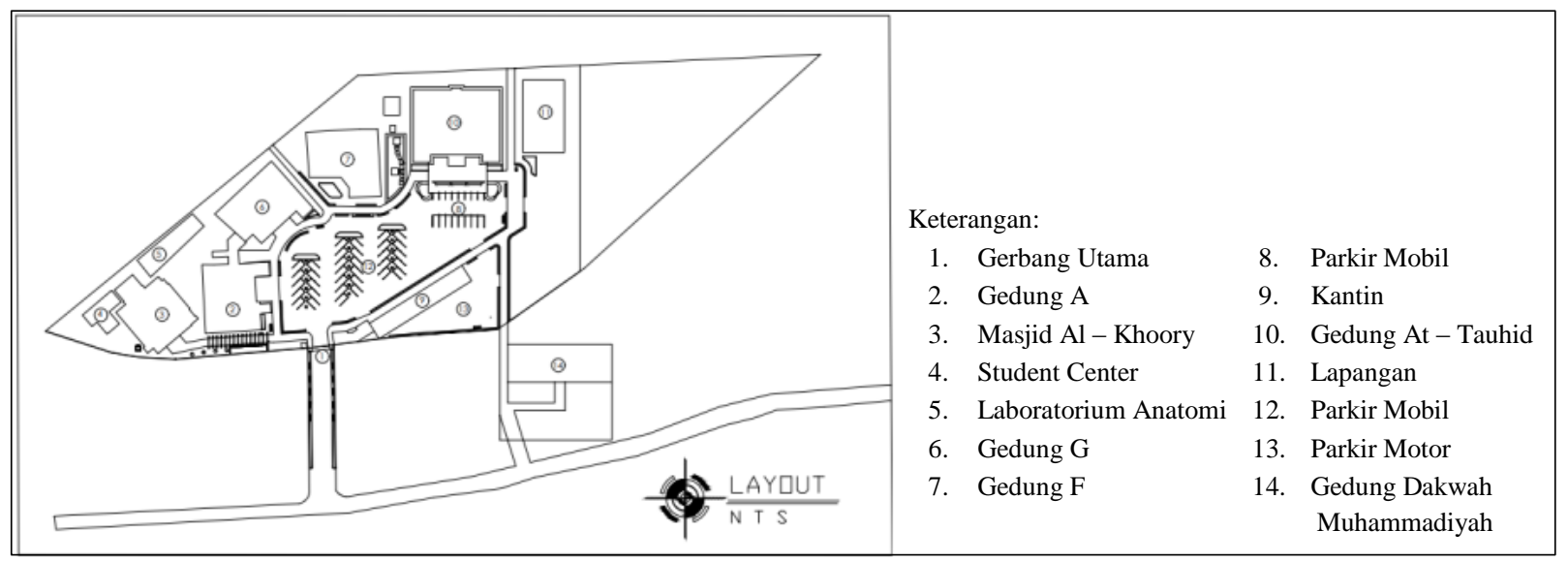

Gambar 1. Layout UM Surabaya.

Berdasarkan hasil observarsi dan penyebaran kuisioner ditemukan jawaban dari masalah penelitian yang ada. Pada observasi ditemukan beberapa elemen citra kota sekala bangunan yang dapat membantu pengguna area kampus untuk berorientasi ketika ingin menuju atau menggunakan fasilitas dan gedung perkuliahan yang ada. Gambar 2, 3, 4, 5, dan 6 berikut merupakan hasil dari observasi lapangan yang berlokasi di UM Surabaya.

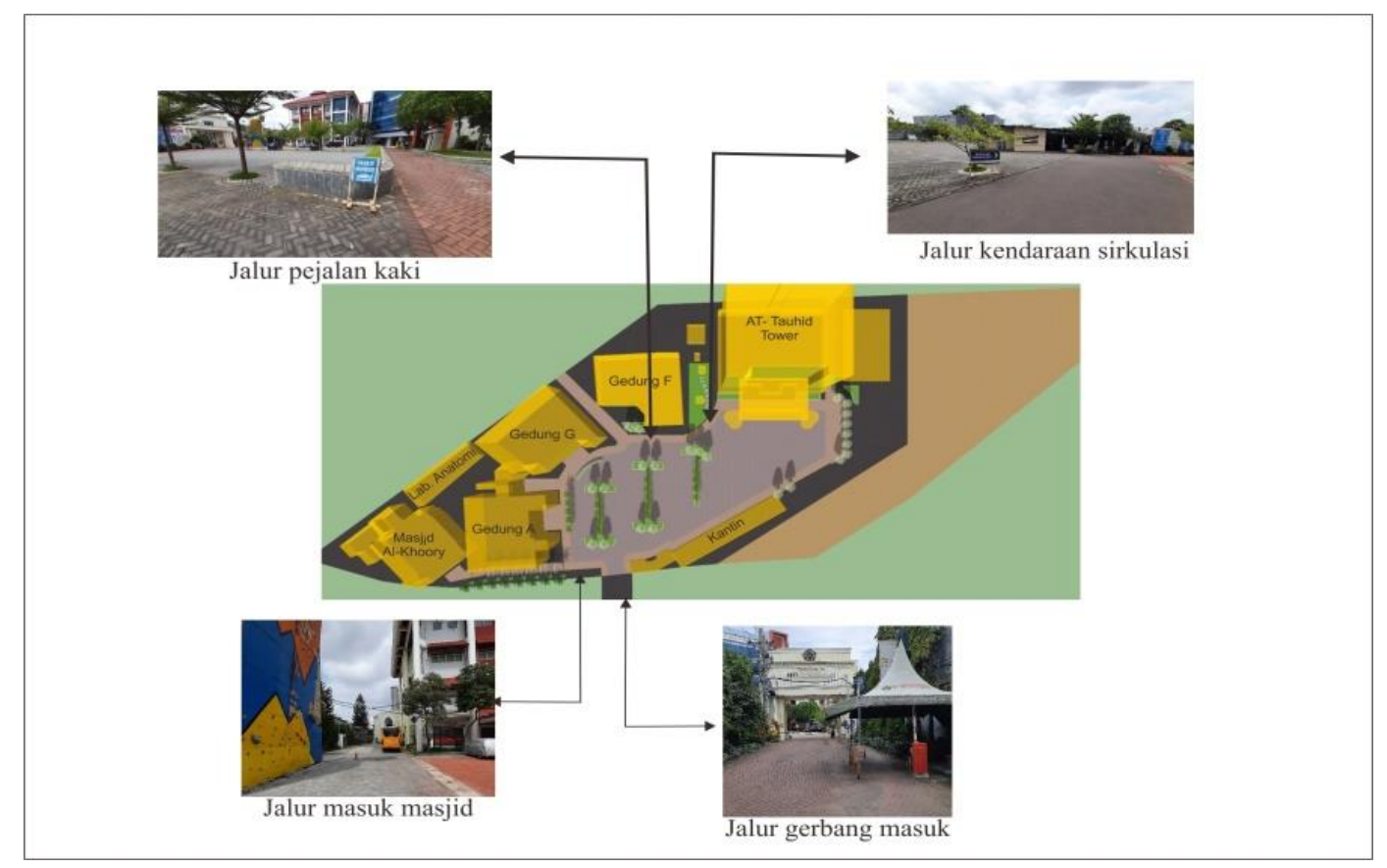

Gambar 2. Contoh jalur yang ada pada UM Surabaya. 


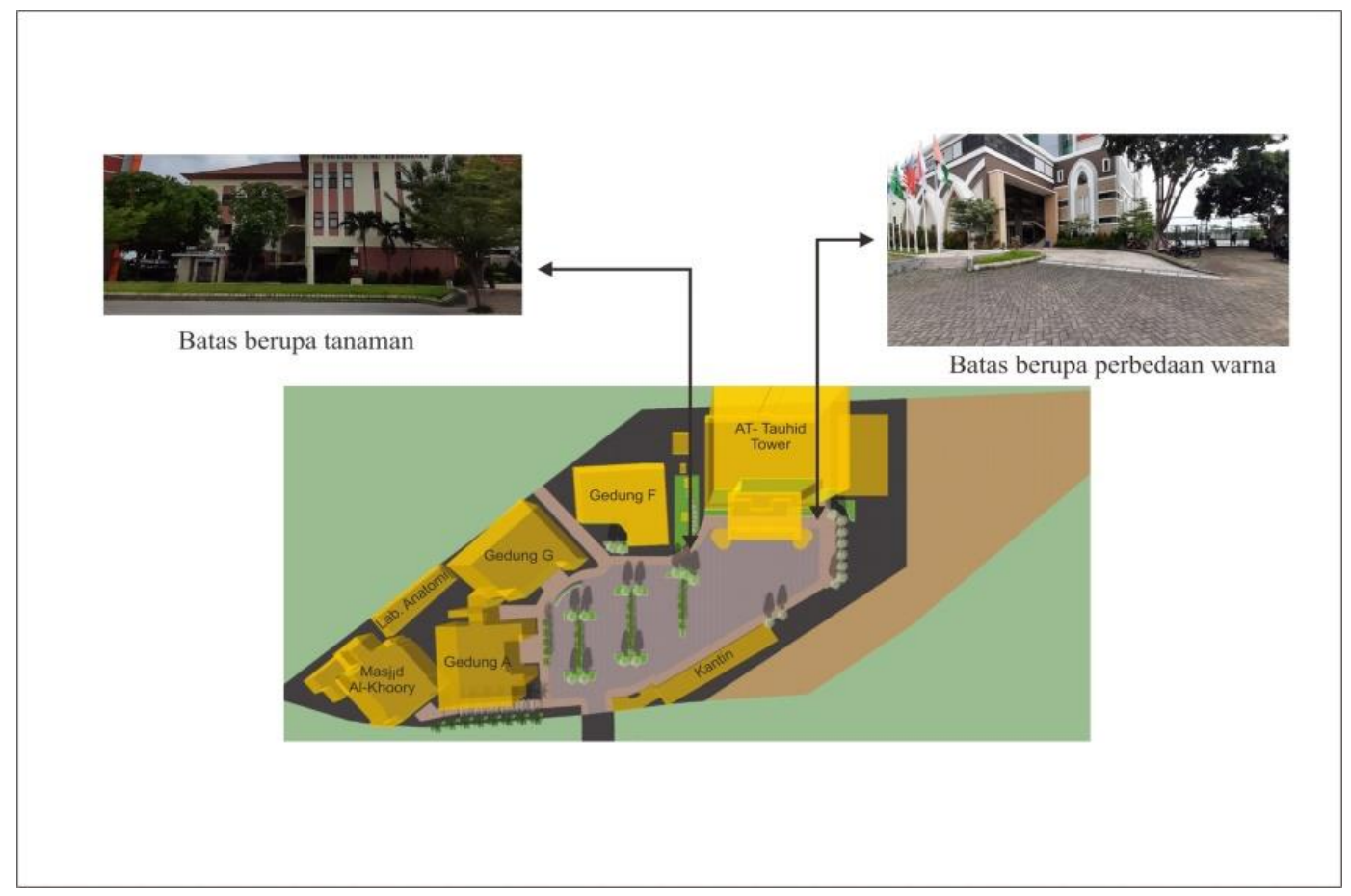

Gambar 3. Contoh batas berupa tanaman

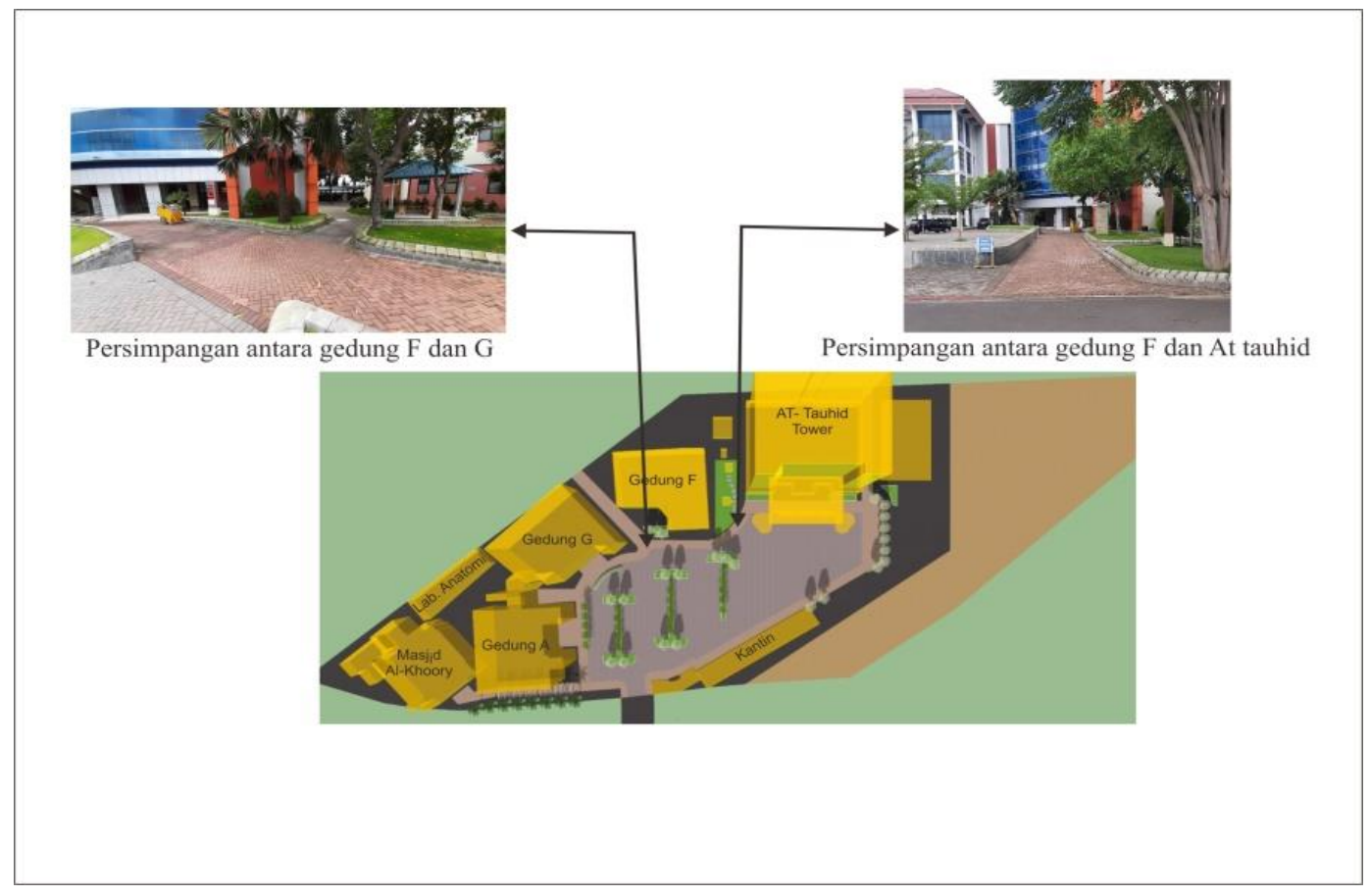

Gambar 4. Contoh simpul atau persimpangan 


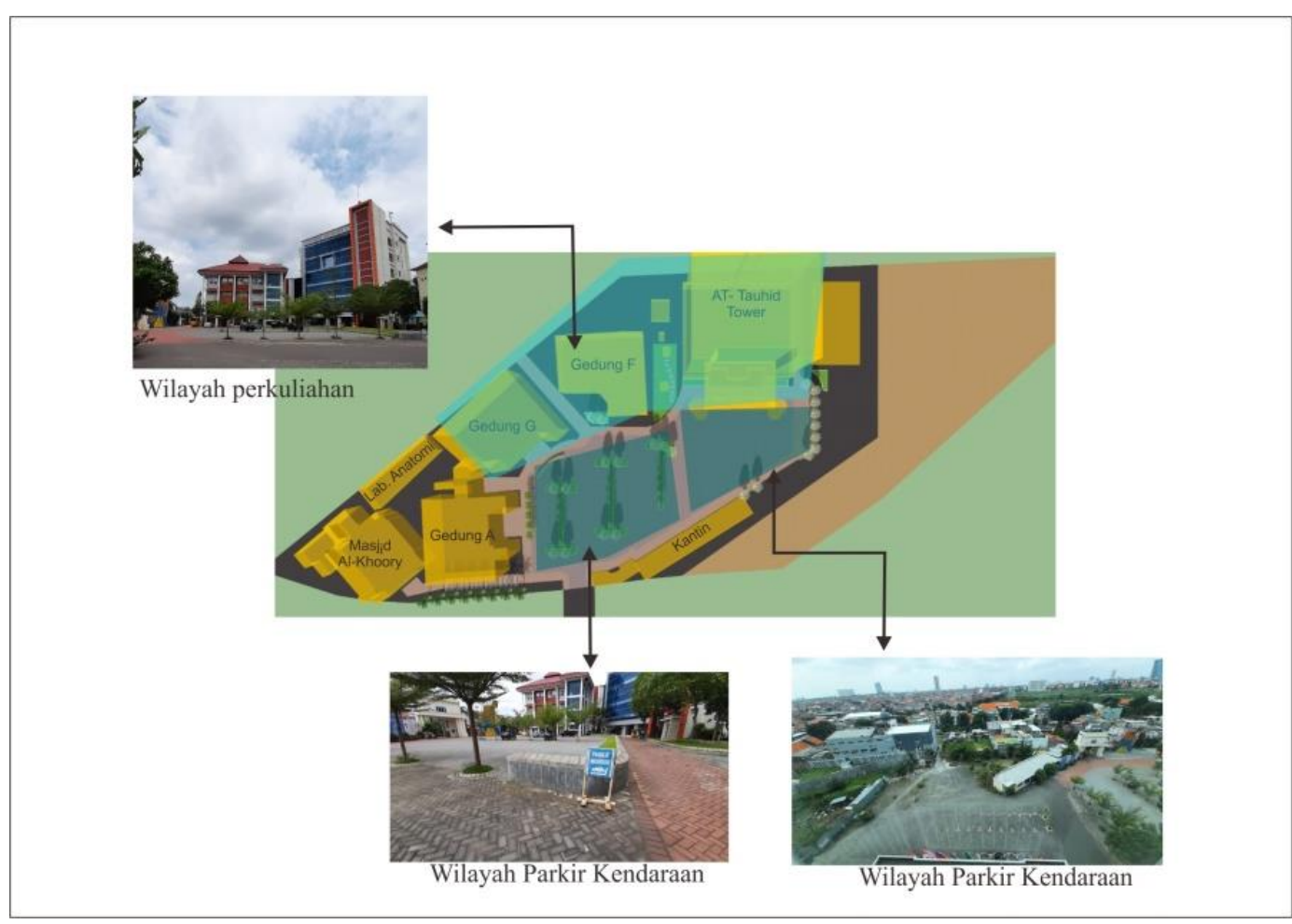

Gambar 5. Contoh wilayah

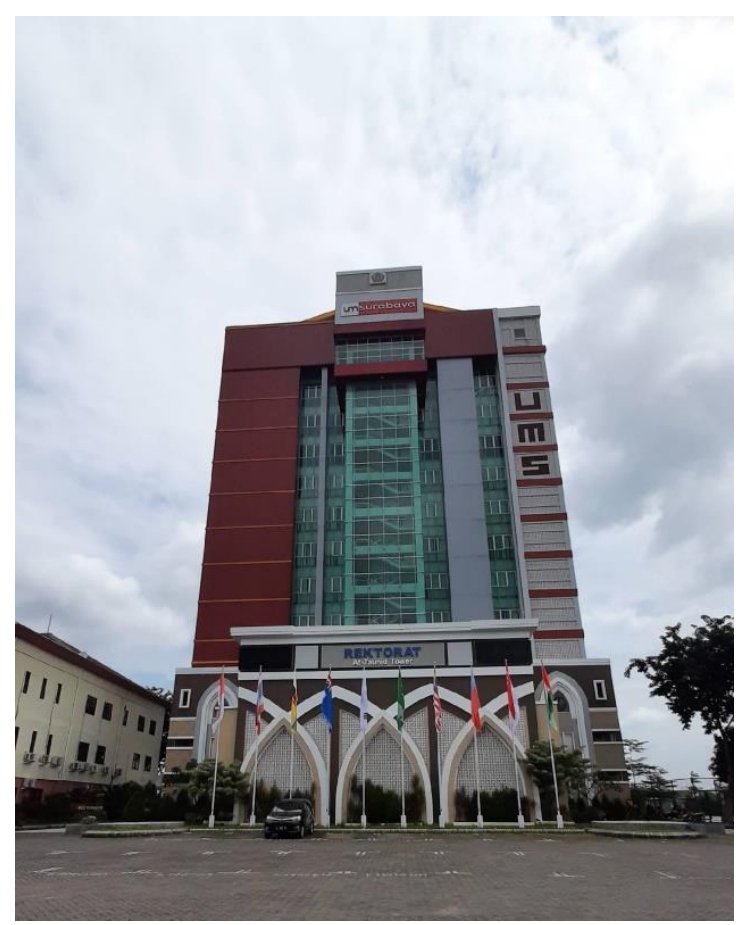

Gambar 6. Landmark dari UM Surabaya

Berdasarkan analisa diatas ditemukan bahwa letak masjid kampus berada di bagian kiri layout dan tertutup oleh gedung sekitarnya. 


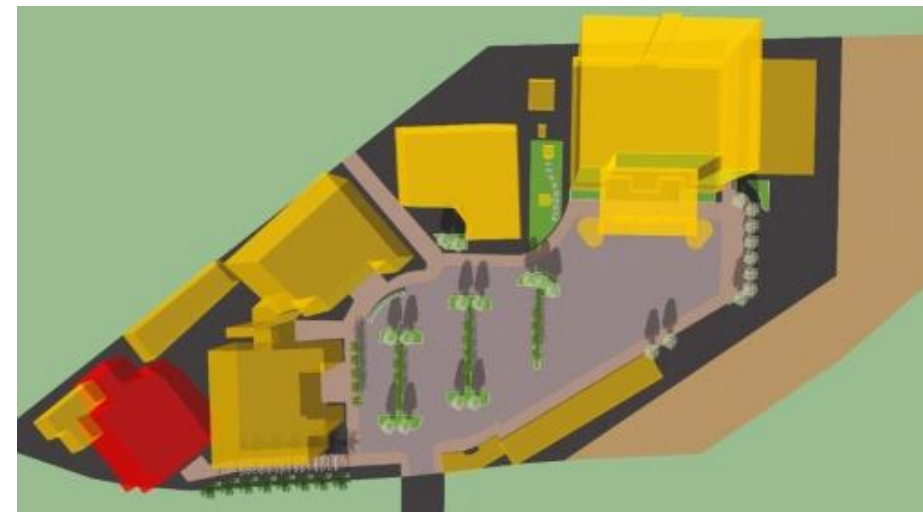

Gambar 7. Layout dan letak Masjid Al-Khoory

Gambar 7 merupakan layout dari Universitas Muhammdiyah Surabaya. Bangunan yang berwarna merah pada gambar layout tersebut merupakan letak Masjid Al-khoory UM Surabaya. Dapat terlihat bahwa letak masjid kampus berada di pojok lahan kampus dan tertutup oleh bangunan yang ada didepannya sehingga tidak dapat dikenali atau terlihat secara langsung

Sementara itu proses way finding Masjid Al-Khoory UM Surabaya ternyata kurang baik terutama bagi pengguna baru di lingkungan UM Surabaya hal tersebut terlihat dari data kuisioner yang telah di sebar pada kalangan dosen, tenaga kependidikan, dan mahasiswa. Koresponden berjumlah 75 orang yang terdiri dari 36 orang merupakan mahasiswa UM Surabaya, dan 39 orang merupakan Dosen atau tenaga kependidikan.

\section{Tata letak masjid kampus tidak strategis 35 jawaban}
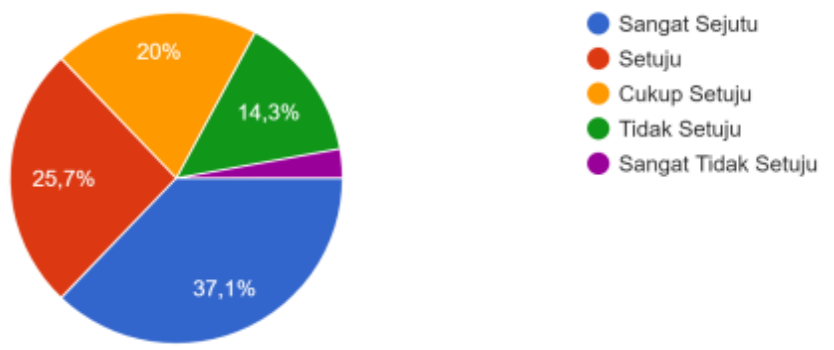

Gambar 8. Hasil Kuisioner Mahasiswa

\section{Tata letak masjid kampus tidak strategis \\ 29 jawaban}

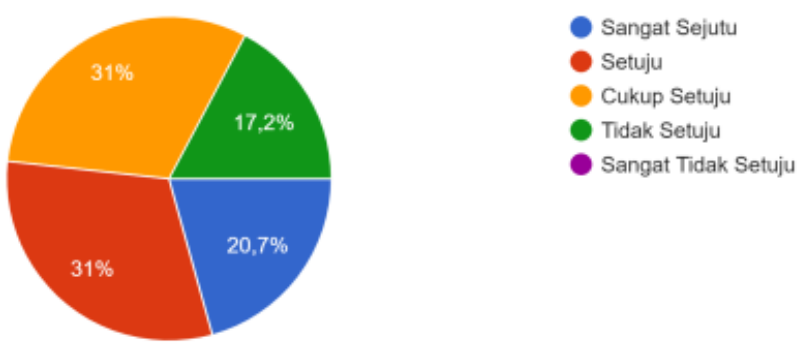

Gambar 9. Hasil Kuisioner Dosen

Sebanyak $44.8 \%$ dari responden dosen dan tenaga pendidik mengalami kesulitan untuk menemukan masjid kampus karena tidak adapnya papan petunjuk arah pada jalur masjid kampus dan sebanuak $42.9 \%$ dari responden mahasiswa juga menyetujii hal tersebut. 
7. Tidak adanya elemen khusus seperti papan petunjuk arah pada jalur masjid kampus membuat anda kebingungan

35 jawaban

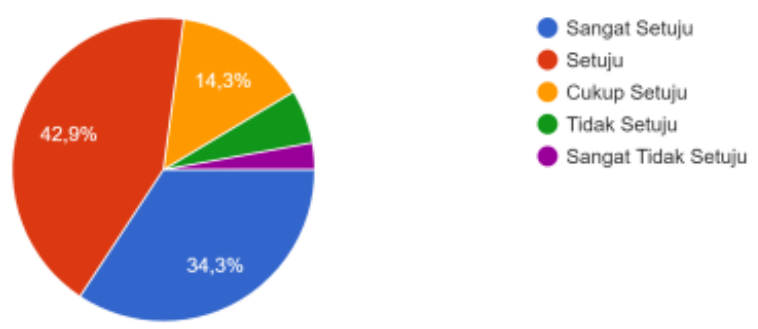

Gambar 10. Hasil Kuisioner Mahasiswa 7. Tidak adanya elemen khusus seperti papan petunjuk arah pada jalur masjid kampus membuat
anda kebingungan
29 jawaban
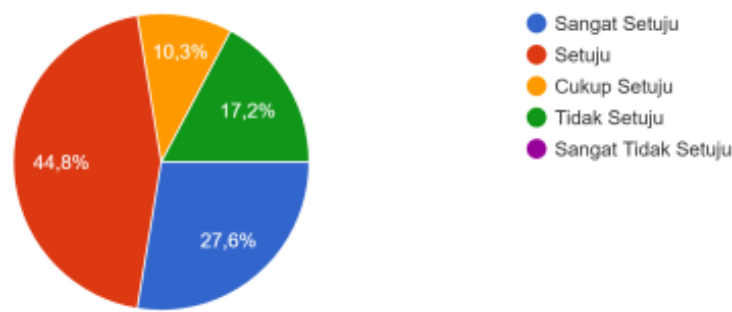

Gambar 11. Hasil Kuisioner Mahasiswa

Dari pembahasan dan penyebaran kuisioner diperlukan sistem penanda yang terintregrasi satu sama lain agar memudahkan pengguna untuk mengetahui lokasi masjid kampus sistem penanda tersebut dapat berupa peta lokasi dan papan informasi terkait gedung beserta fasilitasnya. Peta lokasi dan papan informasi merupakan salah satu wujud gambar penanda visual yang memiliki tujuan untuk menyampaikan informasi dengan ceat dan jelas, yang hampir tanpa teks atau kata-kata. Menurut Santoso, dkk (2013), persepsi visual diproses oleh $80 \%$ otak manusia, sehingga keberadaan penanda visual berpengaruh besar pada penginderaan manusia. Penyajian Peta lokasi dan papan informasi gedung ini pun disajikan dengan pertimbangan akan kemudahan untuk dipahami dan diingat oleh pengguna gedung.

\section{PETA LOKASI}

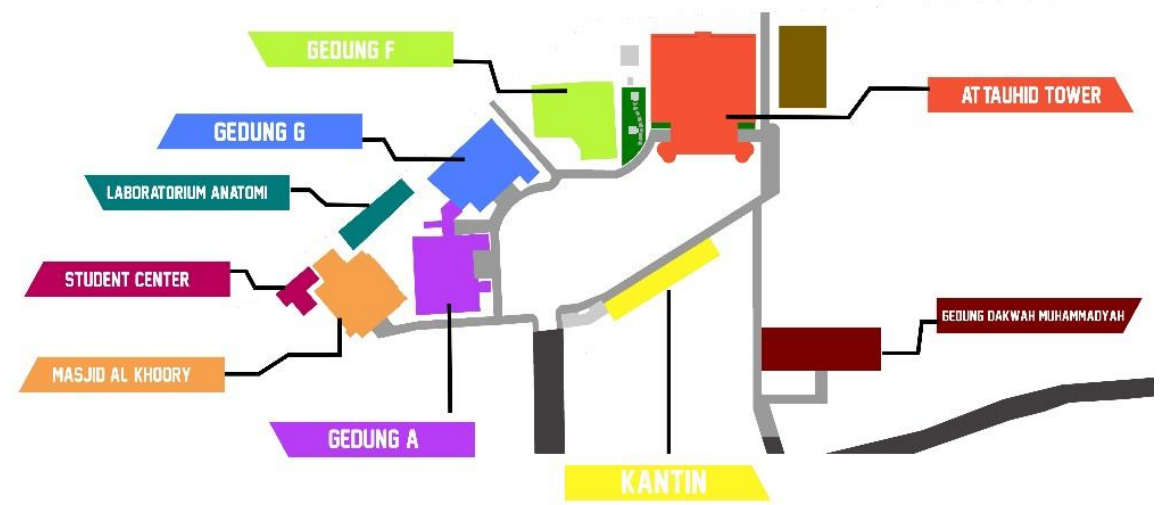

Gambar 12. Desain Peta Lokasi 

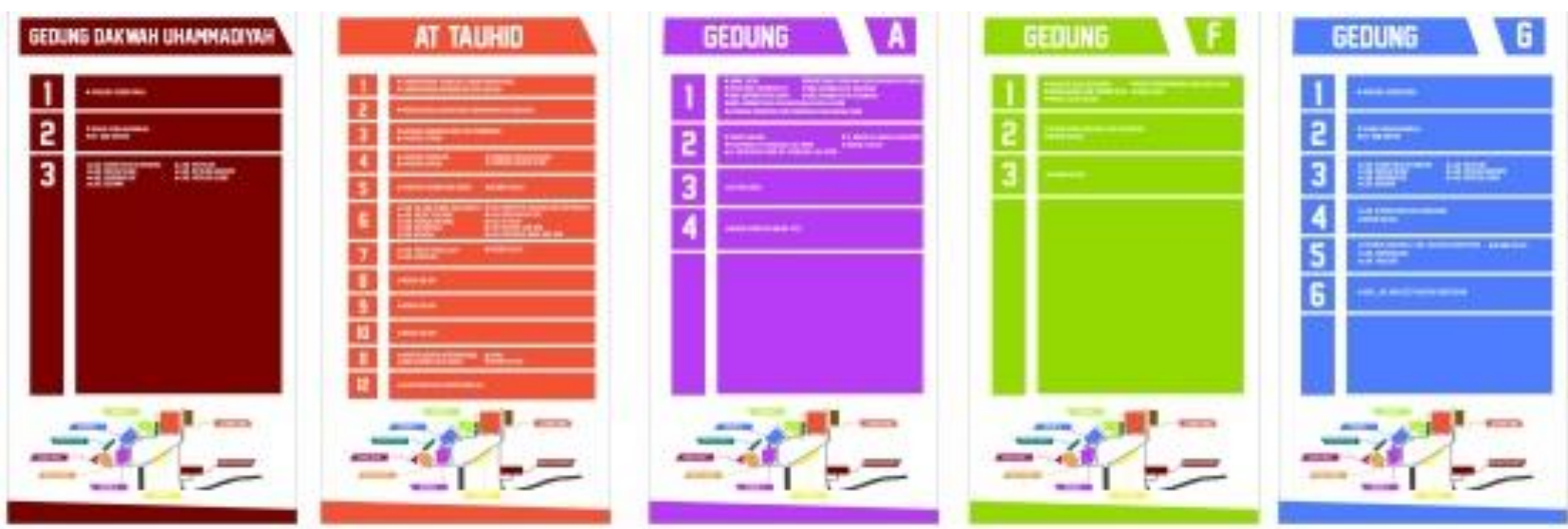

Gambar 13. Rancangan papan informasi gedung

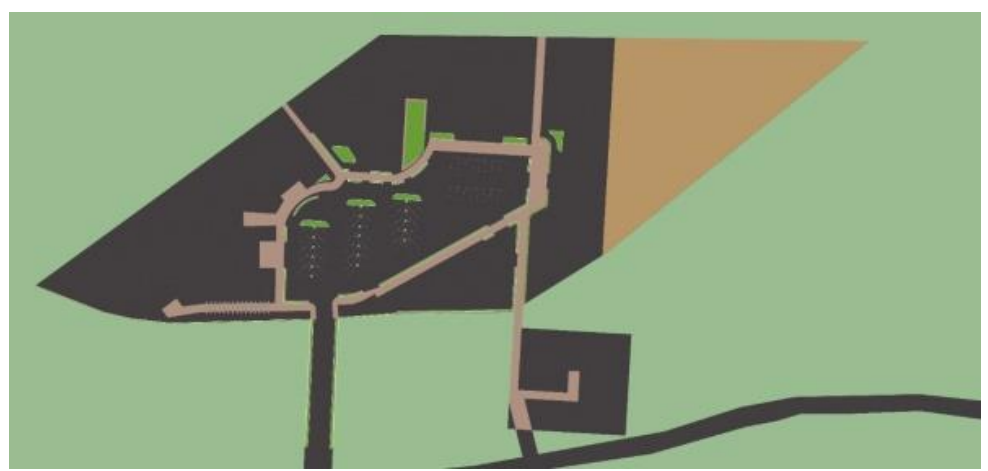

Gambar 14. Rancangan Path

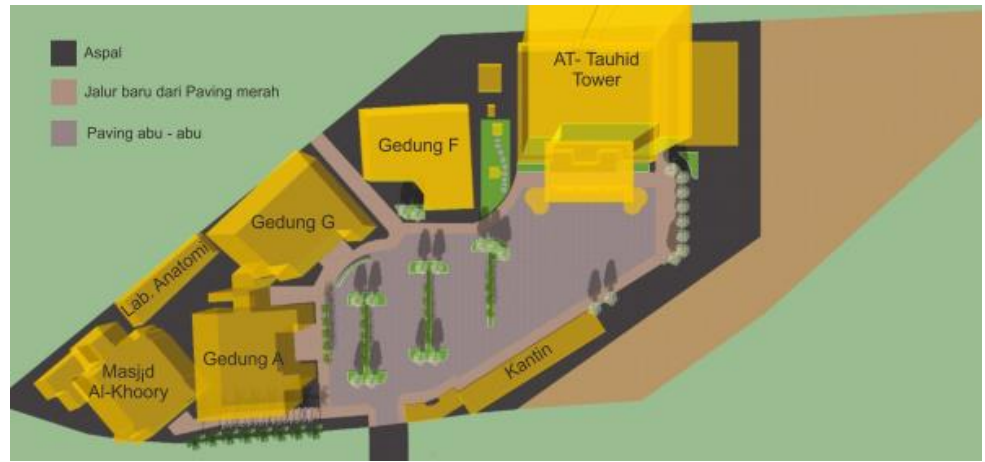

Gambar 15. Perbedaan warna material

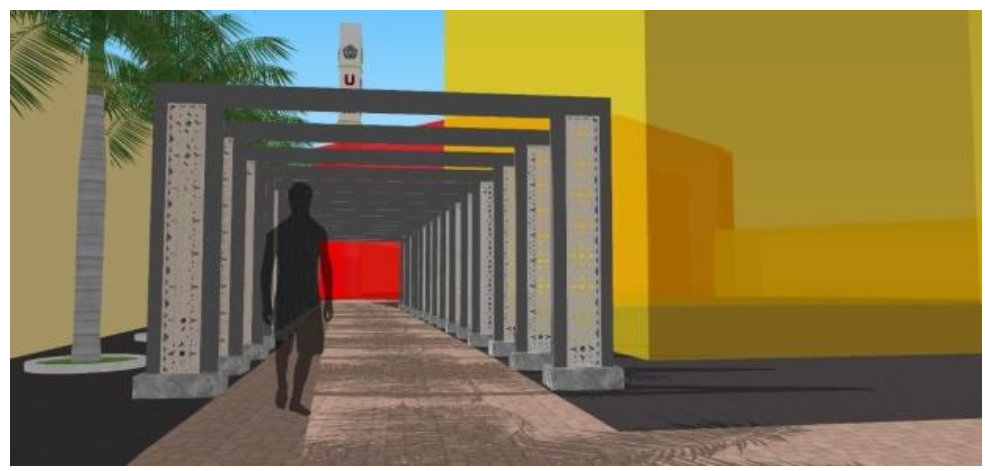

Gambar 16. Rancangan gate masjid 


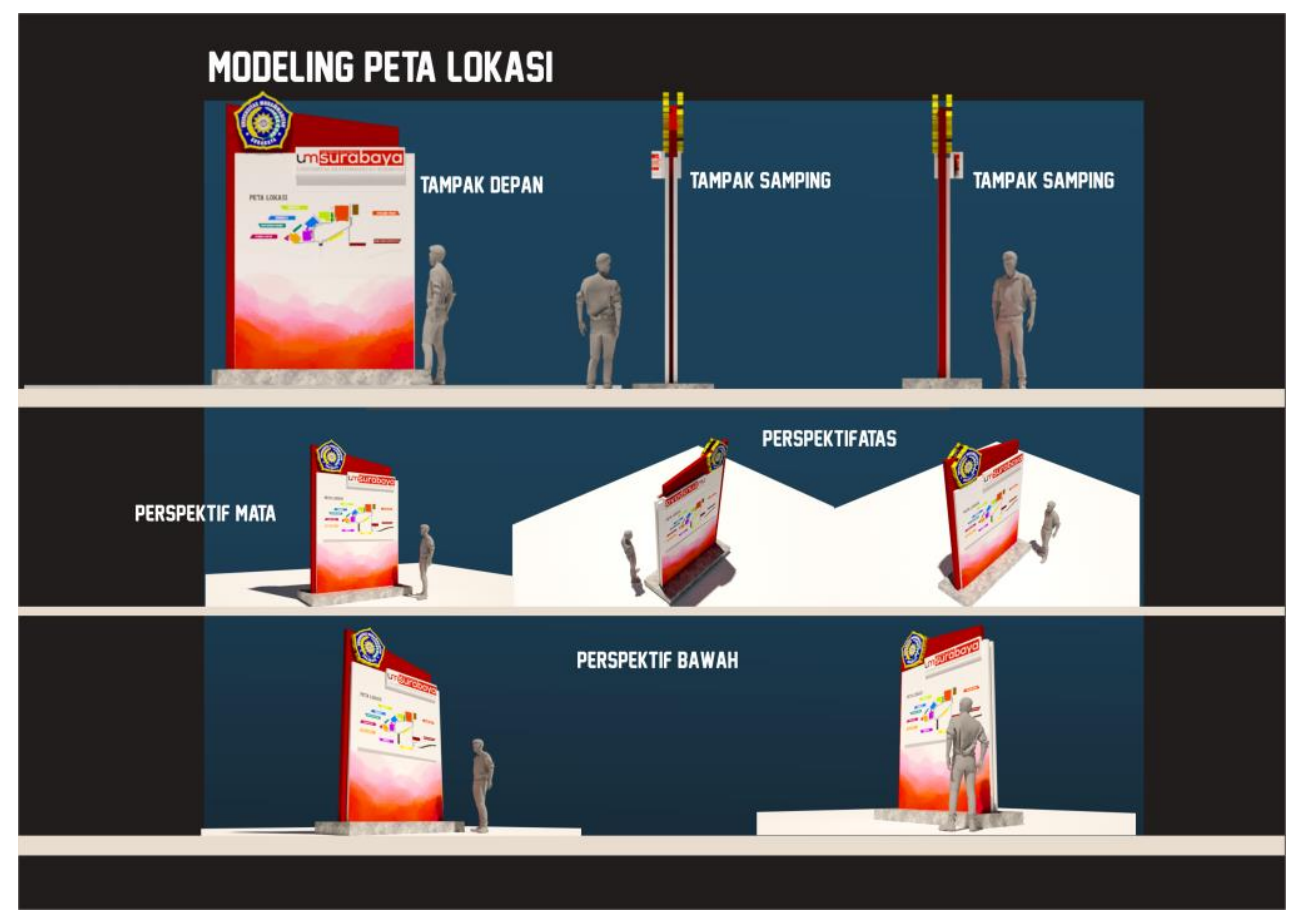

Gambar 17. Modeling 3D Papan Informasi

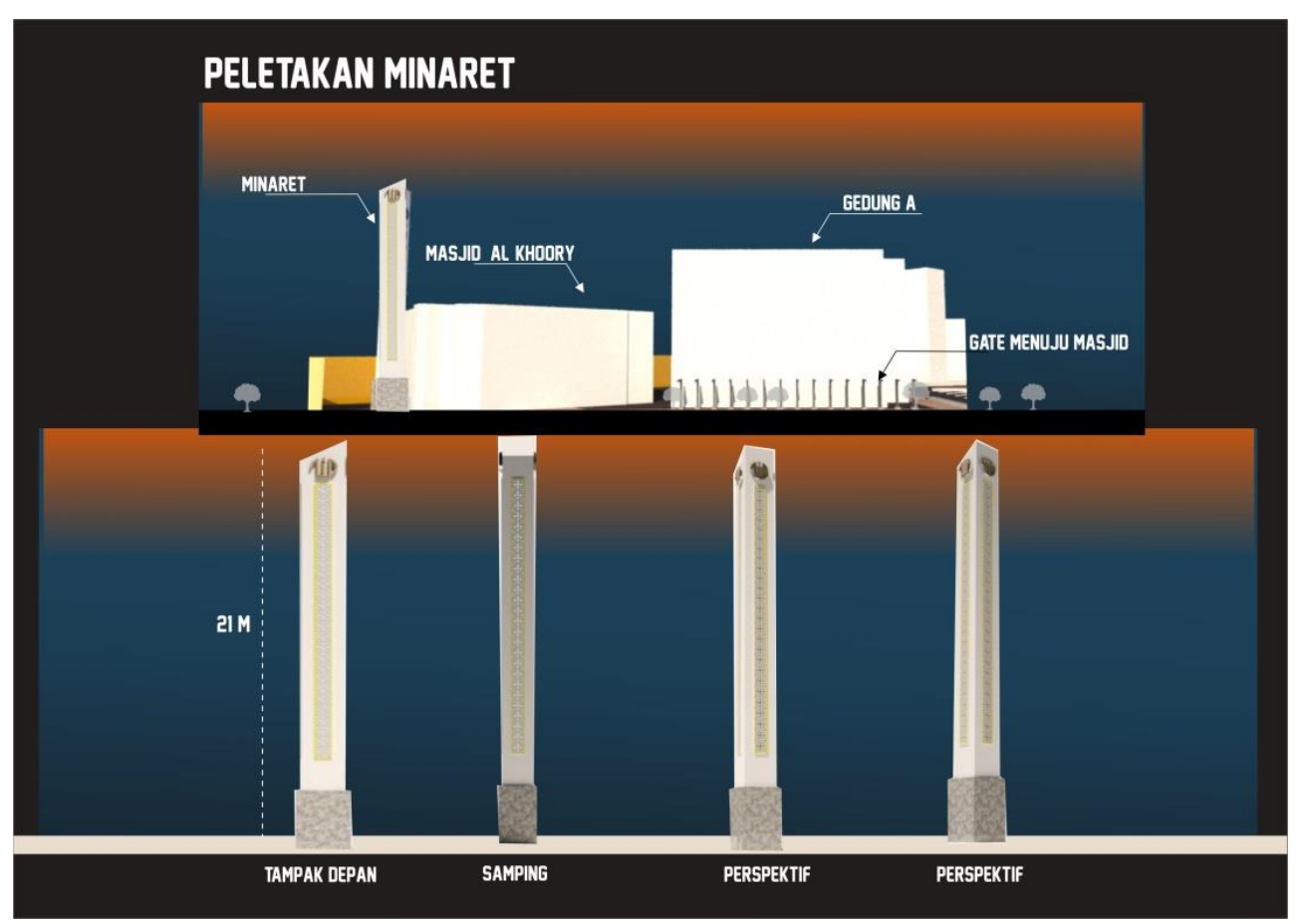

Gambar 18. Rancangan Minaret Masjid Al-Khoory 

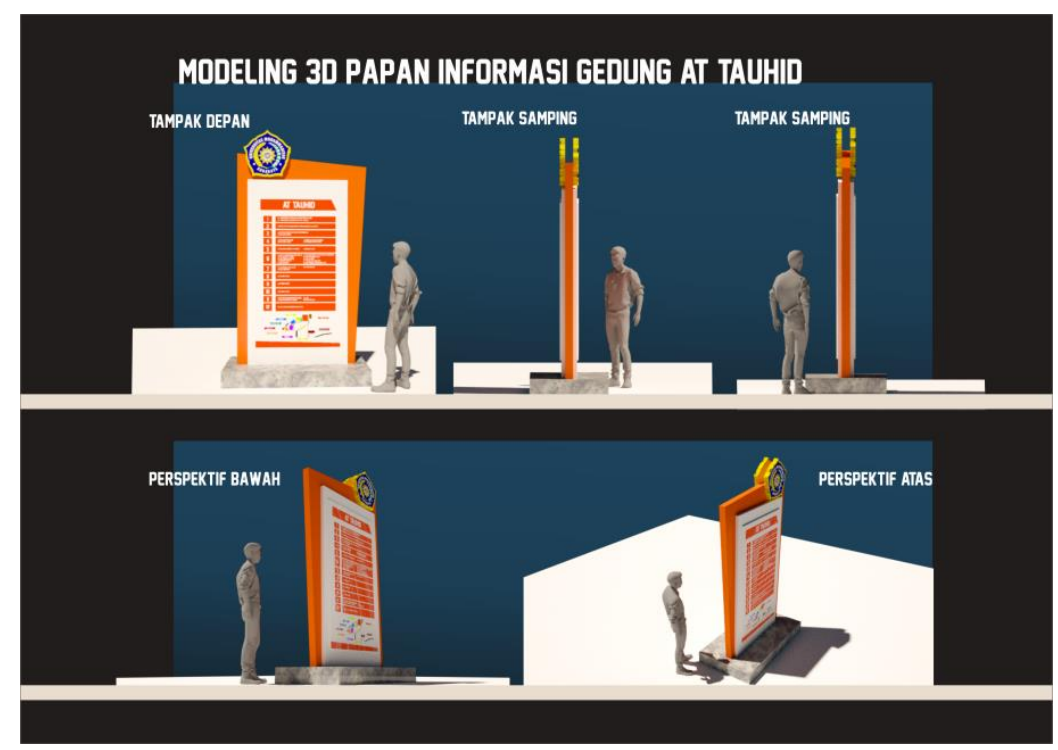

Gambar 19. Modeling 3D Papan Informasi Masjid Al-Khoory

\section{Kesimpulan}

Perlu adanya perbaikan sistem way finding pada wilayah kampus yang dapat memberikan kemudahan bagi warga kampus ataupun masyarakat yang berkunjung di kampus agar dapat menemukan Masjid Al-Khoory dengan baik, seperti: (1) adanya jalur yang ada pada UM Surabaya; (2) penerapan pembatas berupa tanaman; (3) simpul atau persimpangan; (4) pembagian wilayah; dan (5) penempatan Landmark dari UM Surabaya. Perbaikan sistem tersebut berupa rancangan sistem penanda yang memuat informasi terkait layout kampus sehingga para civitas dan pengguna baru khususnya, dapat berorientasi dengan mudah tanpa mengalami disorientasi. Selain itu perlu dirancang minaret sebagai penanda letak Majsid Al-Khoory UM Surabaya.

\section{Referensi}

Afrizal (2016). Metode Penelitian : Sebuah Upaya Mendukung Penggunaan Penelitian Kualitatif Dalam Berbagai Disiplin Ilmu. Jakarta: PT Raja Grafindo Persada.

Beaumont, P.B., Gray, J., Moore, G.T., dan Robinson, B. (1984). Orientation and Wayfinding in the Taurang Departmental Building: A Focused Post Occupancy Evaluation, Ministry of Works and Development Hamilton, New Zealand;

Follis, J. and Hammer, D. and Wnitney Library of Design. (1979). Architectural Signing and Graphics. New York: Whitney Library of Design

Gazalba, Sidi. (1994). Islamic Architecture. Edinburg: Edinburg University Press.

Griffin, EM. (2006). A First Look At Communication Theory, Sixth Edition. New York: McGraw-Hill, Hantari, Ninda Anjas (2020). Wayfinding Dalam Arsitektur. Sinentika Jurnal Arsitektur, 98-103. Diakses 16 Desember 2020, dari Universitas Gajah Mada.

Hunter, S. (2010). Spatial Orientation, Environmental Perception and Wayfinding. New York: University at Buffalo, Center for Inclusive Design and Enivronmental Access.

Husain, Huri Yasin. (2011). Fikih Masjid (terj). Jakarta: Pustaka Al-Kautsar.

Lynch, K., (1960), The Image of the City, Cambridge, Massachusetts: MIT Press.

Passini, P. A. (1992). Wayfinding People Signs, and Architecture. Ontario: McGraw - Hill Ryerson Ltd. Reissued as a collector's edition in 2002 by Focus Strategic Communications, Inc.

Passini, R. (1984). Wayfinding in Architecture, Environmental Design Series volume 4. New York: Van Nostrand Reinhold Company.

Rifa'i, A. Bachrun dan Fakhruroji, Moch. (2005). Manajemen Masjid: Mengoptimalkan Fungsi Sosial - Ekonomi Masjid. Bandung; Benang Merah Press. 
Santoso, M. ., Dedi, D. ., \& Silvia, M. (2013). Perancangan Redesain Sign System Universitas Kristen Petra Surabaya, 6-7. Diakses pada 13 Desember 2020, dari Universitas Kristen Petra Surbaya.

Sevinc, Z., \& Bozkurt, E. (2015). Wayfinding behaviors in a healthcare environment: a case study analysis of individual differences. Gazi University Journal of Science Part B: Art, Humanities, Design and Planning Vol 3 Issue 3, 37-45.

Sumalyo, Yulianto (2006). Arsitektur Mesjid dan Monumen Sejarah Muslim. Yogjakarta: Gajah Mada University Press. 